Original Research Article

\title{
The comparison of clinical efficacy of formoterol and fluticasone versus salmeterol and fluticasone in patients of bronchial asthma
}

\author{
Akashdeep Rattu ${ }^{1}$, Inderpal Kaur ${ }^{1 *}$, Ashok Goel ${ }^{1}$, Nirmal Chand Kajal ${ }^{2}$
}

\begin{abstract}
${ }^{1}$ Department of Pharmacology, ${ }^{2}$ Department of Tuberculosis and Chest Diseases, Government Medical College and Hospital, Amritsar, Punjab, India

Received: 05 March 2018

Revised: 18 March 2018

Accepted: 03 April 2018

*Correspondence to:

Dr. Inderpal Kaur,

Email: inderpalpharma@ gmail.com

Copyright: (C) the author(s), publisher and licensee Medip Academy. This is an openaccess article distributed under the terms of the Creative Commons Attribution NonCommercial License, which permits unrestricted noncommercial use, distribution, and reproduction in any medium, provided the original work is properly cited.
\end{abstract}

\begin{abstract}
Background: Fixed-dose combinations of Inhaled corticosteroids (ICS) and Long acting beta agonist (LABA) are established and widely used treatment for bronchial asthma when ICSs as monotherapy are ineffective. This study attempted to compare the efficacy of salmeterol and fluticasone with formoterol (newer LABA) and fluticasone in patients of bronchial asthma.

Methods: An open label, randomized, prospective, parallel and comparative study of eight-week duration was conducted on 80 patients of bronchial asthma, with the collaboration of Department of pharmacology and Department of Tuberculosis and Chest Diseases Hospital, Government medical college, Amritsar. Patients in Group A were treated with 2 actuations of Formoterol and Fluticasone $(6 / 125 \mu \mathrm{g})$ twice daily and group B patients were treated with 2 actuations of Salmeterol and Fluticasone $(50 / 125 \mu \mathrm{g})$ twice daily for 8 weeks with metered dose inhaler (MDI). Patients in group A and B were assessed on day zero, 4 weeks and 8 weeks for clinical assessment and computerized spirometry for FVC, FEV1, FEV1/FVC and PEFR.

Results: In group A mean \pm SD of FEV1 statistically significantly increased $(<0.001)$ after eight week of therapy $(1.50 \pm 0.12)$ from its baseline values (1.34 \pm 0.11$)$. Similarly, in group B mean \pm SD of FEV1 statistically significantly increased $(<0.001)$ after eight weeks $(1.48 \pm 0.13)$ from its baseline values $(1.36 \pm 0.12)$. There was statistically significant $(<0.001)$ improvement in other parameters of spirometry in patients of both the groups.

Conclusions: It was observed that both the combination of Fluticasone + Formoterol and Fluticasone + Salmeterol are effective in the treatment of bronchial asthma.
\end{abstract}

Keywords: Asthma, LABA, ICS

\section{INTRODUCTION}

Bronchial asthma is a syndrome characterized by episodes of variable obstruction of airway, largely reversible either spontaneously or with treatment. ${ }^{1}$ Asthma affects an estimated 300 million individuals worldwide. Annually, the World Health Organization (WHO) has estimated that 15 million disability adjusted life years are lost and 250,000 asthma deaths are reported worldwide. ${ }^{2}$

Fluticasone is a potent ICS with a well-established efficacy and safety profile. It blocks the late-phase allergen in the response in the lung and decreases airway hyper responsiveness.$^{3,4}$ It is rapidly absorbed from the lungs into the systemic circulation, with a half-life of 7.8 hours. Systemic bioavailability is approximately $17 \% .^{5,6}$ while formoterol and salmeterol are LABA. Formoterol has a rapid onset of action of between 1 and 3 min but both have sustained, dose-dependent bronchodilator effects.

The present study was undertaken to compare the efficacy of ICS/LABA fixed maintenance-dose treatment with formoterol/fluticasone and salmeterol/fluticasone for maintenance and rescue therapy in patients with asthma aged $\geq 18$ years. Study also evaluated the tolerability of a new asthma therapy with combination administered twice 
daily (b.i.d.) via MDI in adult and adolescent patients with moderate asthma.

\section{METHODS}

The present study was an open label, parallel, prospective, randomized, comparative and interventional study of 8 weeks duration, was conducted in the Department of Pharmacology in collaboration with Department of Tuberculosis and Chest Diseases, Government Medical College, Amritsar. Total 80 patients of bronchial asthma of either sex with age 18 to 60 years were enrolled in the study. Spirometry was done by using Spiro meter SpiroExcel by MEDICAID. It's a Digital Spirometer with automatic interpretation by assessment of various parameters viz FVC, $\mathrm{FEV}_{1}, \mathrm{FEV}_{1} / \mathrm{FVC}$, PEFR. After assessment, patients were randomly divided in two groups A and B, comprising of 40 patients each. Each patient was educated and trained for correct use of Metered dose inhaler (MDI).

- Group A patients were treated 2 actuations of Fluticasone + Formoterol $(6 / 125 \mu \mathrm{g})$ using MDI with the interval of 5 minutes, twice daily.

- Group B patients were treated with 2 actuations of Fluticasone + Salmeterol (50/125 $\mu \mathrm{g})$ using MDI with the interval of 5 minutes, twice daily.

For patients using either drug who still suffer acute exacerbations were permitted to take salbutamol (2 actuation of $100 \mu \mathrm{g}$ each) up to 4 occasions per day as reliever medication by Metered dose inhaler. Patients were asked to swish and gargle with water to minimize the chances of oropharyngeal candidiasis.

The approval of ethics committee was taken before the start of study. The patients who met the inclusion criteria were recruited in study after informing the patients regarding the study in their vernacular language and taking written informed consent.

\section{Inclusion criteria}

- $\quad$ Age 18-60 years of either sex

- Newly diagnosed patients with bronchial asthma

- Partly controlled asthma (according to GINA guidelines)

Bronchodilator reversibility $>12 \%$ and $200 \mathrm{ml}$ of $\mathrm{FEV}_{1}$ after salbutamol inhalation (2 actuations, $100 \mu \mathrm{g}$ per actuation) (according to GINA guidelines).

\section{Exclusion criteria}

- Life threatening asthma within past year

- Hospitalization/Emergency department visit in 4weeks prior to screening

- Systemic corticosteroid used in 1 month prior to screening
- Use of Leukotrienes receptor antagonist in week before screening

- Non reversible active pulmonary disease

- Clinically significant Respiratory tract infections

- $\quad$ Recent use of $\beta$ blockers (other than cardio selective $\beta$ blockers), TCA or MAO inhibitors.

- Cor Pulmonale and Ischemic heart disease

- Any previous cardiac interventions

Patients were assessed at the baseline, 4 weeks and 8 weeks of therapy for FVC, FEV $1, \mathrm{FEV}_{1} / \mathrm{FVC}$ and PEFR on computerized spirometry. Patients were advised to report any adverse effect with drug treatment, which was managed accordingly.

Data were statistically described in terms of mean $( \pm \mathrm{SD})$, frequencies (number of cases) and percentages. Data were tested first for normal distribution by KlomogorovSmirnov test. Comparison of quantitative variables between the study groups was done using Student $t$ test for independent samples if normally distributed. MannWhitney U test was used for non-normally distributed quantitative data. For comparing categorical data, Chi square test was performed. Exact test was used instead when the expected frequency is less than 5. Pearson's correlation coefficient was computed to evaluate the correlation between quantitative variables. A probability value ( $\mathrm{p}$ value) less than 0.05 was considered statistically significant. All statistical calculations were done using computer programs Microsoft Excel 2007 (Microsoft Corporation, NY, USA) and SPSS (Statistical Package for the Social Science; SPSS Inc., Chicago, IL, USA) version 21.

\section{RESULTS}

Table 1: Baseline parameters of study groups.

\begin{tabular}{|lll|}
\hline Characteristics & Group A & Group B \\
\hline $\begin{array}{l}\text { Number of } \\
\text { Patients }\end{array}$ & 40 & 40 \\
\hline Age (yrs.) & $39.43 \pm 10.93$ & $38.73 \pm 12.60$ \\
\hline $\begin{array}{l}\text { Gender (Male: } \\
\text { Female) }\end{array}$ & $\begin{array}{l}19: 21 \\
\text { General Examination }\end{array}$ & $18: 22$ \\
\hline Pulse & $78.18 \pm 6.17$ & $79.18 \pm 6.38$ \\
\hline $\begin{array}{l}\text { Respiratory } \\
\text { Rate }\end{array}$ & $\begin{array}{l}19.85 \pm 2.20 \\
\text { Hematological } \\
\text { profile }\end{array}$ & $19.98 \pm 2.25$ \\
\hline Hemoglobin & $0.56 \pm 0.02$ & $0.56 \pm 0.02$ \\
\hline TLC & $11957.50 \pm 3185.70$ & $10822.50 \pm 2364.86$ \\
\hline Neutrophils & $59.55 \pm 8.69$ & $65.29 \pm 10.86$ \\
\hline Monocytes & $9.14 \pm 9.97$ & $6.44 \pm 2.58$ \\
\hline Lymphocytes & $32.42 \pm 7.44$ & $27.53 \pm 9.71$ \\
\hline Eosinophils & $0.42 \pm 0.86$ & $0.77 \pm 1.27$ \\
\hline
\end{tabular}

Total 80 patients were enrolled in the study randomly divided into two groups -group A $(n=40)$ and group B $(n=40)$. Baseline characteristics like demographic profile 
and hematological parameters, observed in patients of both the groups during the study period as given in the Table 1.

All the values at each follow up were significantly better than baseline in both groups but statistically nonsignificant difference observed between the two groups at each follow up (Table 2).

Table 2: Comparison of FEV1 values with two inhalers.

\begin{tabular}{|llllll|}
\hline \multirow{2}{*}{ FEV } & Group & N & Mean & SD & $\begin{array}{l}\text { p- } \\
\text { value }\end{array}$ \\
\hline \multirow{2}{*}{ Baseline } & A & 40 & 1.34 & 0.11 & 0.636 \\
\cline { 2 - 6 } & B & 40 & 1.36 & 0.12 & \\
\hline \multirow{2}{*}{ 4 weeks } & A & 40 & 1.45 & 0.10 & 0.268 \\
\cline { 2 - 6 } & B & 40 & 1.42 & 0.13 & \\
\hline \multirow{2}{*}{ 8 weeks } & A & 40 & 1.50 & 0.12 & 0.651 \\
\cline { 2 - 6 } & B & 40 & 1.48 & 0.13 & \\
\hline
\end{tabular}

Table 3: Comparison of FVC values with two inhalers.

\begin{tabular}{|llllll|}
\hline \multirow{2}{*}{ FVC } & Group & N & Mean & SD & $\begin{array}{l}\text { p- } \\
\text { value }\end{array}$ \\
\hline \multirow{2}{*}{ Baseline } & A & 40 & 2.39 & 0.15 & 0.678 \\
\cline { 2 - 6 } & B & 40 & 2.40 & 0.15 & \\
\hline \multirow{2}{*}{ 4 weeks } & A & 40 & 2.45 & 0.17 & 0.955 \\
\cline { 2 - 6 } & B & 40 & 2.45 & 0.15 & \\
\hline \multirow{2}{*}{ 8 weeks } & A & 40 & 2.48 & 0.19 & 0.909 \\
\cline { 2 - 6 } & B & 40 & 2.49 & 0.16 & \\
\hline
\end{tabular}

All the values at each follow up were significantly better than baseline in both groups but statistically nonsignificant difference observed between the two groups at each follow up (Table 3).
All the values at each follow up were significantly better than baseline in both groups but statistically nonsignificant difference observed between the two groups at each follow up (Table 4).

\section{Table 4: Comparison of FEV1/FVC values with} two inhalers.

\begin{tabular}{|llllll|}
\hline \hline $\begin{array}{l}\text { FEV } 1 / \\
\text { FVC }\end{array}$ & Group & N & Mean & SD & $\begin{array}{l}\text { p - } \\
\text { value }\end{array}$ \\
\hline \multirow{2}{*}{ Baseline } & A & 40 & 0.56 & 0.02 & 0.777 \\
\cline { 2 - 6 } & B & 40 & 0.56 & 0.02 & \\
\hline \multirow{2}{*}{ 4 weeks } & A & 40 & 0.59 & 0.03 & 0.093 \\
\cline { 2 - 6 } & B & 40 & 0.58 & 0.04 & \\
\hline \multirow{2}{*}{8 weeks } & A & 40 & 0.60 & 0.03 & 0.293 \\
\cline { 2 - 6 } & B & 40 & 0.60 & 0.03 & \\
\hline
\end{tabular}

Table 5: Comparison of PEFR values with two inhalers.

\begin{tabular}{|llllll|}
\hline PEFR & Group & $\mathbf{N}$ & Mean & SD & $\begin{array}{l}\mathbf{p} \text { - } \\
\text { value }\end{array}$ \\
\hline \multirow{2}{*}{ Baseline } & A & 40 & 4.41 & 0.52 & 0.419 \\
\cline { 2 - 6 } & B & 40 & 4.32 & 0.47 & \\
\hline \multirow{2}{*}{ 4 weeks } & A & 40 & 4.54 & 0.49 & 0.111 \\
\cline { 2 - 6 } & B & 40 & 4.38 & 0.39 & \\
\hline \multirow{2}{*}{8 weeks } & A & 40 & 4.55 & 0.45 & 0.285 \\
\cline { 2 - 6 } & B & 40 & 4.45 & 0.35 & \\
\hline
\end{tabular}

All the values at each follow up were significantly better than baseline in both groups but statistically nonsignificant difference observed between the two groups at each follow up (Table 5).

Table 6: Comparison of spirometry parameters improvements.

\begin{tabular}{|llllll|}
\hline \multirow{2}{*}{ Parameters } & Group & Mean (baseline) & Mean (8weeks) & \% Change & p-value \\
\hline \multirow{2}{*}{ FEV $_{1}$} & A & $2.39 \pm 0.15$ & $2.48 \pm 0.19$ & 3.76 & $<0.001$ \\
\cline { 2 - 6 } & B & $2.40 \pm 0.15$ & $2.49 \pm 0.16$ & 3.75 & $<0.001$ \\
\hline \multirow{2}{*}{ PEFR } & A & $1.34 \pm 0.11$ & $1.50 \pm 0.12$ & 11.94 & $<0.001$ \\
\cline { 2 - 6 } & B & $1.36 \pm 0.12$ & $1.48 \pm 0.13$ & 8.82 & $<0.001$ \\
\hline \multirow{2}{*}{ FEV1/FVC } & A & $4.41 \pm 0.52$ & $4.55 \pm 0.45$ & 3.17 & $<0.001$ \\
\cline { 2 - 6 } & B & $4.32 \pm 0.47$ & $4.45 \pm 0.35$ & 3 & $<0.001$ \\
\cline { 2 - 6 } & B & $0.56 \pm 0.02$ & $0.60 \pm 0.03$ & 7.14 & $<0.001$ \\
\hline
\end{tabular}

Table 7: Parameter changes at 4 and 8 weeks.

\begin{tabular}{|c|c|c|c|c|c|}
\hline \multirow{2}{*}{ Parameters } & \multirow{2}{*}{ Group } & \multicolumn{2}{|l|}{ Mean \pm SD } & \multicolumn{2}{|l|}{ p- value } \\
\hline & & (4 weeks) & (8 weeks) & (4 weeks) & (8 weeks) \\
\hline \multirow{2}{*}{ Rescue Doses } & A & $3.25 \pm 2.92$ & $0.58 \pm 0.84$ & \multirow{2}{*}{0.45} & \multirow{2}{*}{0.57} \\
\hline & B & $3.75 \pm 2.97$ & $0.48 \pm 0.75$ & & \\
\hline \multirow{2}{*}{ Night time awakenings } & A & $0.68 \pm 1.14$ & $0.05 \pm 0.22$ & \multirow{2}{*}{0.92} & \multirow{2}{*}{0.56} \\
\hline & B & $0.70 \pm 1.11$ & $0.03 \pm 0.16$ & & \\
\hline
\end{tabular}


Statistically significant improvement was observed in spirometry parameters (FVC, FEV ${ }_{1}$, PEFR, FEV1/FVC) in both the groups $\mathrm{A}$ and $\mathrm{B}$ after 8 weeks of therapy as compare to baseline values (Table 6).

Mean number of rescue doses and night awakening events were reduced with treatment in both the groups from 4 weeks to 8 weeks, but the difference between the two groups were statistically non-significant $(\mathrm{p}>0.05)$.

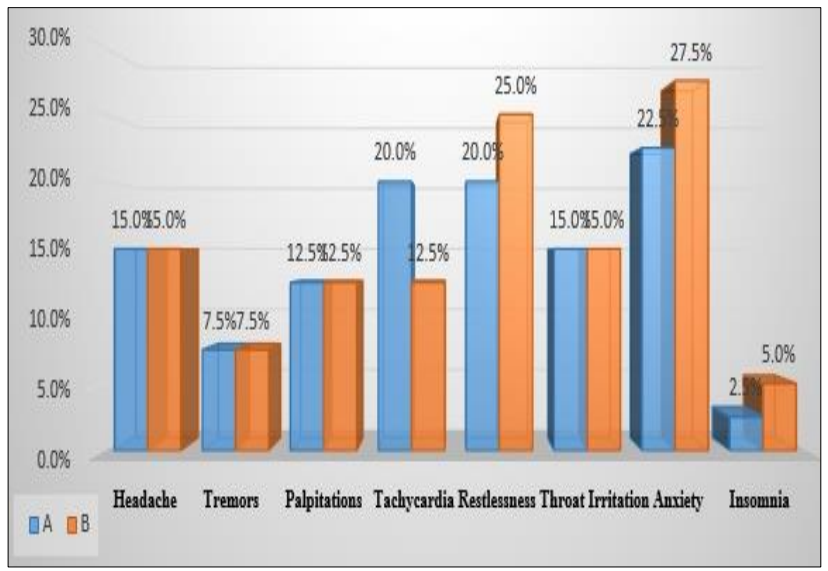

Figure 1: Comparison of adverse drug reactions.

During the study period, there was no serious adverse drug reaction observed in both the groups. Group B patients had comparatively more anxiety and restlessness whereas tachycardia was more common in group A. But all gets improved gradually and both the drugs were well tolerated over the 8-week study period.

\section{DISCUSSION}

In group A, there were 19 (47.5\%) females and 21 (52.5\%) males and group B, there were 18 (45\%) females and 22 (55\%) males. Mean age for group A was 39.4 years and that for group B was 38.7 years. Hence, groups A and B were comparable at baseline as the difference between age and sex were statistically non-significant ( $\mathrm{p}$-value 0.791 and 1.0 respectively) (Table 1 ).

Common symptoms reported in this study were chest tightness/breathlessness with cough and wheezing which were improved significantly with the treatment in patients of both groups. Need for rescue doses with salbutamol and number of night awakenings also decreased in both the groups (Table 7) which is in consistence with previous study. ${ }^{7}$

Tachycardia was more commonly observed in patients of group A, whereas restlessness, anxiety and insomnia were mostly seen in patients of group B than group A but these are statistically non-significant $[(p>0.05)$ Figure 1$]$. But all the side effects improved gradually and tolerance developed over the 8-week study period, with no serious drug-related adverse events.
Both the combinations of fluticasone with formoterol and salmeterol were effective in significantly improving pulmonary function tests - FVC, FEV1, FEV1/FVC and PEFR at both follow-up visits.

\section{Group A (Fluticasone and Formoterol)}

In Group A patients, mean of percent predicted FEV1 improved from baseline to 8 weeks was found to be $11.94 \%$ and is statistically significant $(\mathrm{p}<0.001)$. Percent at baseline predicted values of FVC and PEFR were $3.76 \%$ and $3.17 \%$ respectively at 8 weeks compared to baseline, which is statistically significant $(\mathrm{p}<0.001)$. Mean percent improvement in FEV1/FVC at 8 weeks from baseline was $7.14 \%$, which is statistically significant $(\mathrm{p}<0.001)$ (Table 6). Similar improvement in pulmonary function tests on treatment with fluticasone and formoterol was observed in previously done studies. ${ }^{8}$

\section{Group B (Fluticasone and Salmeterol)}

In Group B patients, mean percent improvement in FEV1 from baseline to 8 weeks was found to be $8.82 \%$ and is statistically significant (p <0.001). mean percent improvement in FVC and PEFR were $3.75 \%$ and $3 \%$ respectively at 8 weeks compared to baseline, which is statistically significant (p <0.001). Mean percent improvement in FEV1/FVC at 8 weeks from baseline was $7.14 \%$, which is statistically significant $(\mathrm{p}<0.001)$ (Table 6). Similar improvement was observed in pulmonary function test parameters on treatment with fluticasone and salmeterol in previously done studies. ${ }^{9}$

\section{Group A versus Group B}

\section{FVC}

Mean change in FVC at 4 weeks and 8 weeks in group A was higher than mean change in FVC in group B patients. But result found to be statistically non-significant ( $p>$ 0.05) (Table 3).

\section{FEV1}

Mean change in FEV1 at 4 weeks and 8 weeks in group A was higher than mean change in FEV1 in group B patients. But result found to be statistically non-significant $(p>$ 0.05) (Table 2).

\section{PEFR}

Mean change in PEFR at 4 weeks and 8 weeks in group A was higher than mean change in PEFR in group B patients. But result found to be statistically non-significant ( $p>$ 0.05 ) (Table 5).

\section{FEV $1 / F V C$}

Mean change in FEV1/FVC at 4 weeks and 8 weeks in group A was higher than mean change in FEV1/FVC in 
group B patients. But result found to be statistically nonsignificant $(\mathrm{p}>0.05)$ (Table 4).

Comparison between the two groups on the basis of improvement in pulmonary function tests (FVC, FEV1, PEFR and FEV1/FVC) demonstrated no significant change at the end of the study period as depicted in previous studies. ${ }^{7,10}$

\section{Funding: No funding sources}

Conflict of interest: None declared

Ethical approval: The study was approved by the Institutional Ethics Committee

\section{REFERENCES}

1. Kasper DL, editor. Harrison's principles of internal medicine. 19th edition / editors, Dennis L. Kasper, MD, William Ellery Channing, Professor of Medicine, Professor of Microbiology, Department of Microbiology and Immunobiology, Harvard Medical School, Division of Infectious Diseases, Brigham and Women's Hospital, Boston, Massachusetts [and five others]. New York: McGraw Hill Education; 2015:1.

2. Bateman ED, Hurd SS, Barnes PJ, Bousquet J, Drazen JM, FitzGerald M, et al. Global strategy for asthma management and prevention: GINA executive summary. Eur Respir J. 2008 Jan;31(1):143-78.

3. Berger WE, Ford LB, Mahr T, Nathan RA, Crim C, Edwards L, et al. Efficacy and safety of fluticasone propionate 250 microg administered once daily in patients with persistent asthma treated with or without inhaled corticosteroids. Ann Allergy Asthma Immunol Off Publ Am Coll Allergy Asthma Immunol. 2002 Oct;89(4):393-9.

4. Sovijarvi A, Haahtela $\mathrm{T}$, Ekroos H, Lindqvist A, Saarinen A, Poussa T, et al. Sustained reduction in bronchial hyperresponsiveness with inhaled fluticasone propionate within three days in mild asthma: time course after onset and cessation of treatment. Thorax. 2003 Jun;58(6):500-4.

5. Crim C, Pierre LN, Daley-Yates PT. A review of the pharmacology and pharmacokinetics of inhaled fluticasone propionate and mometasone furoate. Clin Ther. 2001 Sep;23(9):1339-54.

6. Daley-Yates PT, Parkins DA. Systemic bioavailability of hydrofluoroalkane formulations containing fluticasone propionate and salmeterol. $\mathrm{Br} \mathrm{J}$ Clin Pharmacol. 2011 Aug;72(2):353-4.

7. Bodzenta-Lukaszyk A, Dymek A, McAulay K, Mansikka H. Fluticasone/formoterol combination therapy is as effective as fluticasone/salmeterol in the treatment of asthma but has a more rapid onset of action: an open-label, randomized study. BMC Pulm Med. 2011 May 23;11:28.

8. Tan RA, Corren J. Clinical utility and development of the fluticasone/formoterol combination formulation (Flutiform ${ }^{\circledR)}$ ) for the treatment of asthma. Drug Des Devel Ther. 2014 Sep 30;8:1555-61.

9. Shapiro G, Lumry W, Wolfe J, Given J, White MV, Woodring A, et al. Combined salmeterol 50 microg and fluticasone propionate 250 microg in the diskus device for the treatment of asthma. Am J Respir Crit Care Med. 2000 Feb;161(2 Pt 1):527-34.

10. Sirisha GM. Comparison of Safety and Action of Salmeterol and Formoterol in Combination with Fluticasone Propionate in Asthma Patients. Sch Acad J Pharm. 2013;26:452-7.

Cite this article as: Rattu A, Kaur I, Goel A, Kajal NC. The comparison of clinical efficacy of formoterol and fluticasone versus salmeterol and fluticasone in patients of bronchial asthma. Int $\mathrm{J}$ Basic Clin Pharmacol 2018;7:947-51. 